\title{
Emerging role of dipeptidyl peptidase-4 inhibitors in the management of type 2 diabetes
}

\author{
Bernd Richter \\ Elizabeth Bandeira-Echtler \\ Karla Bergerhoff \\ Christian Lerch \\ Cochrane Metabolic and Endocrine \\ Disorders Group, Department of \\ General Practice, Heinrich-Heine \\ University Duesseldorf, Duesseldorf, \\ Germany
}

Background: In type 2 diabetes mellitus (T2DM) there is a progressive loss of $\beta$-cell function. One new approach yielding promising results is the use of the orally active dipeptidyl peptidase- 4 (DPP-4) inhibitors. However, every new compound for T2DM has to prove long-term safety especially on cardiovascular outcomes.

Objectives: Systematic review and meta-analysis of the effects of sitagliptin and vildagliptin therapy on main efficacy parameters and safety.

Selection criteria, data collection, and analysis: Randomized controlled clinical studies of at least 12 weeks' duration in T2DM.

Results: DPP-4 inhibitors versus placebo showed glycosylated hemoglobin $\mathrm{A}_{1 \mathrm{c}}$ (A1c) improvements of $0.7 \%$ versus placebo but not compared to monotherapy with other hypoglycemic agents $(0.3 \%$ in favor of controls). The overall risk profile of DPP-4 inhibitors was low, however a $34 \%$ relative risk increase ( $95 \%$ confidence interval $10 \%$ to $64 \%, \mathrm{P}=0.004$ ) was noted for all-cause infection associated with sitagliptin use. No data on immune function, health-related quality of life and diabetic complications could be extracted.

Conclusions: DPP-4 inhibitors have some theoretical advantages over existing therapies with oral antidiabetic compounds but should currently be restricted to individual patients. Long-term data on cardiovascular outcomes and safety are needed before widespread use of these new agents.

Keywords: DPP-4 inhibitors, sitagliptin, vildagliptin, systematic review, meta-analysis

\section{Introduction to management issues of T2DM}

In type 2 diabetes mellitus (T2DM), the actions and secretion of insulin are impaired, as opposed to the absolute deficiency of insulin that occurs with type 1 diabetes mellitus. Type 2 diabetes is characterized by two major pathophysiologic defects: (1) insulin resistance, which results in increased hepatic glucose production and decreased peripheral glucose disposal, and (2) impaired $\beta$-cell secretory function (Bloomgarden 2007). Insulin resistance is an impaired biological response to the effects of exogenous or endogenous insulin. Insulin resistance in the hepatic and peripheral tissues, particularly skeletal muscle, leads to unrestrained hepatic glucose production and diminished insulin-stimulated peripheral glucose uptake and utilization (DeFronzo et al 1992). Insulin secretion by the pancreatic $\beta$-cell is initially sufficient to compensate for insulin resistance, thereby maintaining normal blood glucose levels. Hyperinsulinemia, which accompanies insulin resistance, can maintain sufficiently normal glucose metabolism as long as pancreatic $\beta$-cell function remains normal. However, in patients who may develop type 2 diabetes, insulin secretion eventually fails, leading to hyperglycaemia and clinical diabetes (Kahn et al 2006). Individuals with type 2 diabetes may have few or no classic clinical symptoms of hyperglycemia (Ruige et al 1997). The difficulty in maintaining metabolic control, for example measured by glycosylated hemoglobin $A_{1 c}$ (A1c) over time, may be related 
to several behavioral factors (for example difficulties with healthy eating, exercise, medication regimens) but primarily reflects the underlying progressive decline in $\beta$-cell function (UKPDS-16 1995).

Type 2 diabetes has traditionally been treated in a stepwise manner, starting with lifestyle modifications, exercise and later on pharmacotherapy with oral agents. Several classes of oral agents are available for clinical use. These mainly include insulin secretagogues, drugs that delay the absorption of carbohydrates from the gastrointestinal tract, and insulin sensitizers. Over time, many patients with type 2 diabetes will require insulin therapy.

Diabetes has long been recognized as a strong, independent risk factor for cardiovascular disease, a problem which accounts for approximately $70 \%$ of all mortality in people with diabetes (Laakso 1999; Ford 2005). Prospective studies show that compared with their nondiabetic counterparts, the relative risk of cardiovascular mortality for men with diabetes is two to three and for women with diabetes is three to four (Manson et al 1991; Stamler et al 1993). The increased cardiovascular risk associated with diabetes is reflected in the observation that middle-aged individuals with diabetes have mortality and morbidity risks that are similar to nondiabetic individuals who have already suffered a cardiovascular event (Haffner et al 1998).

Both epidemiological and prospective data have demonstrated that treatment of hyperglycemia in T2DM is effective in reducing the risk of microvascular disease (for example diabetic retinopathy) but is less potent in reducing that of myocardial infarction, stroke, and peripheral vascular disease. Treatment of other cardiovascular risk factors, although by definition less prevalent than hyperglycemia, appears to be more effective in preventing macrovascular disease than treatment of hyperglycemia.

The United Kingdom Prospective Diabetes Study (UKPDS) tested mainly whether intensive glucose control with either a sulphonylurea or insulin influences the risk of micro- and macrovascular complications compared with conventional treatment (UKPDS-33 1998). The 10-year results of the UKPDS evaluated drug treatment in nonobese and obese participants with newly diagnosed type 2 diabetes who were referred to hospital clinics. Over 10 years, A1c was $7.0 \%$ in the intensive group compared with $7.9 \%$ in the conventional group. Less than half of US adults with type 2 diabetes reach an A1c level of less than 7\% despite various available therapies (Resnick et al 2006).

The UKPDS had a factorial design meaning that another study investigating intensive versus regular blood pressure control (HDS 1993; UKPDS-38 1998) was imbedded in the main study. Intensive versus conventional glucose control did not result in a statistically significant difference in diabetes related mortality or macrovascular disease endpoints but reduced the relative risk in the 'any diabetes related aggregate endpoint' (Freemantle et al 2003). In the UKPDS, the number needed to treat (NNT) to prevent one patient developing any of the single endpoints over 10 years was 20 (95\% confidence interval [CI] 10 to 500) patients (UKPDS-33 1998). In contrast to these results, publication of the UKPDS-34 (1998), which focused on obese patients with newly diagnosed type 2 diabetes, found several clinically important differences in macrovascular disease endpoints with 10 years of treatment with metformin. In particular, the absolute risk reduction for the aggregate endpoints was more than $10 \%$ and for overall mortality was $7 \%$, giving NNTs of 10 and 14, respectively, over 10 years (McCormack and Greenhalgh 2000).

The UKPDS was criticized on several grounds especially emphasizing hidden biases in interpreting the results of this randomized controlled trial (Ewart 2001; McCormack and Greenhalgh 2000; Nathan 1998). Moreover, the UKPDS-38, investigating tight versus less tight blood pressure control with the use of an angiotensin-converting enzyme inhibitor captopril or a $\beta$-blocker atenolol as main treatment, showed relative risk reductions (in the group assigned to tight control compared with that assigned to less tight control) of $24 \%$ in diabetes related endpoints, $32 \%$ in deaths related to diabetes, $44 \%$ in strokes and $37 \%$ in microvascular endpoints (UKPDS-38 1998).

As type 2 diabetes develops, there is a progressive loss of $\beta$-cell function and intensification of therapy is often required over time. Currently available therapies for T2DM have various limitations and may also be associated with an increased risk of hypoglycemia (eg, sulphonylureas, insulin), weight gain (eg, sulphonylureas, thiazolidinediones, insulin), and gastrointestinal side effects (eg, metformin) as well as edema and heart failure (eg, thiazolidinediones).

Research into the pathophysiology of diabetes has demonstrated that a complex interplay of hormonal and neural stimuli, not just insulin and glucagon, are involved in the regulation of glucometabolic control (Drucker and Nauck 2006).

One new approach yielding promising results is the use of agents that are based on gut incretin hormones, which appear to be malfunctioning in type 2 diabetes mellitus and have important effects on insulin and glucagon biology as well as central nervous system effects on appetite. These 
new treatments include glucose-dependent insulinotropic peptide (GIP) and glucagon-like peptide-1 (GLP-1) ("incretin") mimetics as well as dipeptidyl peptidase-4 (DPP-4) inhibitors. In April 2005, the US Food and Drug Administration (FDA) approved the first incretin mimetic, exenatide, a GLP-1 receptor analogue which is resistant to DPP-4 degradation. Because GLP-1 analogues require injection, much effort has been allocated to create an oral agent targeting the incretin pathway.

The other approach for GLP-1 based therapy is to inhibit the enzyme activity of DPP-4. Several DPP-4 inhibitors are orally active and potentiate and prolong the effects of the incretins. Currently, most experience exists for sitagliptin and vildagliptin, which both have a long duration of action, allowing once daily administration.

Depending on the benefit-risk ratio it might happen that DPP-4 inhibitors will be a first-line treatment strategy of the early stages of type 2 diabetes in the future, particularly in combination with metformin. On the other hand, any new compound in the treatment of type 2 diabetes mellitus, has to prove long-term safety and efficacy. Apart from surrogate outcomes like reductions in fasting plasma glucose or A1c, patient-important endpoints such as effects on cardiovascular disease should be the prime target of diabetes research (Cleland and Atkin 2007; Montori et al 2007).

The focus of this review is on clinical studies of at least 12 weeks' duration investigating the benefit-risk ratio of DPP-4 inhibitor therapy in type 2 diabetic people.

\section{Mode of action, pharmacology, and pharmacokinetic/-dynamic profile of DPP-4 inhibitors \\ The two incretin hormones}

An incretin hormone is a gut hormone that is released into the blood after meal ingestion and stimulates insulin secretion in a glucose-dependent manner. This accounts for the marked prandial insulin response, which prevents prandial hyperglycemia. The incretin concept was established in the 1960s and it was later demonstrated that, for a given rise in plasma glucose concentration, the increase in plasma insulin is approximately threefold greater when glucose is administered orally compared with intravenously (Kreymann et al 1987; Creutzfeld 2005).

The most important incretin hormones are the glucosedependent insulinotropic peptide (GIP) and GLP-1 (Effendic and Portwood 2004). GLP-1 is a 30 amino acid polypeptide, which is produced by the intestinal L-cells localized mainly in the distal portion of the small intestine and in the large intestine. GIP is a 42 amino acid polypeptide, which originates from the intestinal K-cells localized mainly in the duodenum. However, L-cells are also found in the duodenum and endocrine cells also co-express GLP-1 and GIP (Mortensen et al 2003).

GIP and GLP-1 are thought to be responsible for the full incretin effect. Patients with type 2 diabetes exhibit an attenuated insulinotropic action of GIP but not GLP-1 and a significant reduction in meal-stimulated levels of GLP-1 (Nauck et al 1993; Toft-Nielsen et al 2001). Because GLP-1 effects remain relatively intact in type 2 diabetic patients, most pharmaceutical efforts try to potentiate incretin action through GLP-1 mimetics or agonists.

As GIP and GLP-1 together are responsible for the incretin effect in healthy people, the incretin defect in T2DM could theoretically arise because of impaired secretion, accelerated metabolism, defective function of the incretin hormones or their associated receptors, increased activity of DPP-4 (Mannucci et al 2005) as well as through additional mechanisms, eg, action of neuropeptides (Nauck and El-Ouaghlidi 2005). Therefore, several mechanisms may explain the reduced incretin action in type 2 diabetes.

Plasma concentrations of both incretins increase within 5 to 15 min after meal ingestion: GLP-1 is primarily released by the ingestion of carbohydrate, fat and protein, whereas GIP is mainly liberated by the ingestion of carbohydrate and fat (Deacon 2005). Up to two-thirds of the insulin normally secreted in relation to a meal are thought to be a result of the effects of these hormones.

The actions of both incretins depend on glucose concentration, and their function ceases when serum glucose level is less than $55 \mathrm{mg} / \mathrm{dL}$ (3.1 mmol/L) (Drucker et al 1987). After their release, the two hormones circulate in the blood and reach their target cells to activate their receptors.

The interaction of the incretins with their G-protein coupled receptor, which is expressed on pancreatic $\beta$-cells, is the increased formation of cyclic adenosine 30, 50-monophosphate (cAMP), which activates protein kinase A (PKA). This closes adenosine triphosphate (ATP)regulated potassium channels in the presence of elevated glucose levels (Gromada et al 1998; Light et al 2002) and inhibits voltage-dependent potassium channels (MacDonald et al 2002) leading to an increase in intracellular calciumenhancing exocytosis of insulin-containing granules (Gromada et al 1998). 
Both GIP and GLP-1 receptors are expressed in various tissues. GLP-1 receptors are found in pancreatic islets, vagal nerves, stomach, lung, kidney, and the brain, whereas GIP receptors are expressed in pancreatic islets, the brain and adipose tissue (Mayo et al 2003; Wideman and Kieffer 2004).

Besides the direct stimulation of islet $\beta$-cells, GLP-1 may also promote insulin secretion indirectly through the activation of sensory nerves (Ahrén 2004) suggesting an important neural contribution to GLP-1-induced insulin secretion, which could explain the rapid insulinotropic action after meal ingestion (Holst and Deacon 2005).

Direct effects of GLP-1 on $\beta$-cell growth and survival could be demonstrated in animal models, with GLP-1 stimulated proliferation and differentiation of new $\beta$-cells together with an inhibition of $\beta$-cell apoptosis (Xu et al 1999; Perfetti et al 2000; Stoffers et al 2000; Farilla et al 2003). These effects lead to an increased $\beta$-cell mass.

Moreover, GLP-1 suppresses glucagon secretion in a glucose-dependent manner and is not thought to impair the glucagon counter-regulatory response to hypoglycemia (Nauck et al 2002). GLP-1 inhibits gastric emptying and food ingestion, thus reducing meal-associated increases in glycemic excursions, and may enhance glucose disposal and insulin sensitivity (Drucker and Nauck 2006).

\section{Mechanism of action of DPP-4 inhibition}

GLP-1 itself is unpromising as maintenance therapy of diabetes, because the hormone is rapidly inactivated by the action of DPP-4 (Deacon 2004). Both GLP-1 and GIP are inactivated by DPP-4 resulting in a short half-life, which is 1 to $2 \mathrm{~min}$ for GLP-1 and 5 to 7 min for GIP (Deacon 2005). Almost $50 \%$ of this degradation occurs at the intestinal capillaries close to the site of GLP-1 and GIP release. GIPinhibition is probably less important for the antidiabetic actions of DPP-4 inhibitors, since GIP seems to have lost much of its insulinotropic action in type 2 diabetes (Meier and Nauck 2004). As a result of DPP-4 activity, intact, biologically active GLP-1 represents only $10 \%$ to $20 \%$ of total plasma GLP-1 (Deacon et al 1995).

The strategy of inhibiting DPP-4 is to prevent the inactivation of GLP-1 and therefore to enhance and prolong the effects of the endogenously released incretin hormone. It could be demonstrated that DPP-4 inhibition increases circulating levels of GLP-1 in experimental animals and that the insulinotropic action of exogenously administered GLP-1 is intensified by DPP-4 inhibition (Holst and Deacon
1998). DPP-4 inhibition increases not only prandial but also fasting levels of active GLP-1 and results in an overall increase in GLP-1 levels with maintenance of circadian rhythm throughout the day.

Through preventing the rapid degradation of incretin hormones, DPP-4 inhibitors result in postprandial increases in levels of biologically active intact GLP-1 and reduce glucose production from the liver by inhibition of glucagon from the $\alpha$-cells of the pancreas and increasing insulin production. Three DPP-4 inhibitors are currently in late-stage development: vildagliptin, sitagliptin and saxagliptin. Sitagliptin received FDA approval as well as European Medicines Agency (EMEA) marketing authorization. Vildagliptin was also granted EMEA marketing authorization.

DPP-4 acts by cleavage of the two N-terminal amino acids of bioactive peptides, provided that the second amino acid is alanine or proline. Since the second N-terminal amino acid in GLP-1 is alanine, GLP-1 is cleaved to a truncated form (Deacon 2004) which is largely inactive; therefore the cleavage of GLP-1 by DPP-4 is an inactivation process. The cleavage is rapid, which is the reason why native GLP-1 has a short half-life (less than $2 \mathrm{~min}$ ).

DPP-4, also known as the lymphocyte cell surface marker CD 26, is a ubiquitous complex enzyme that exists as a membrane-spanning cell-surface aminopeptidase that transmits intracellular signals via a short intracellular tail and a second smaller soluble form circulating in the plasma (Lambeir et al 2003). It is widely expressed in many tissues, such as liver, lung, kidney, intestine, lymphocytes, capillary endothelium and T-cells, B-cells and natural killer cells (Mentlein 1999; De Meester et al 2000).

As a T-cell costimulator, DPP-4 is of importance in the immune system. The extracellular domain of DPP-4 can also be cleaved from its membrane-anchored form and circulate in plasma, where it retains its full enzymatic activity. DPP-4 preferentially cleaves peptides with a proline or alanine residue in the second aminoterminal position. Many gastrointestinal hormones, neuropeptides, cytokines, and chemokines as well as the endogenous physiological compounds GIP and GLP-1 are substrates for DPP-4 (De Meester et al 2003).

DPP-4 is a member of a complex gene family including fibroblast activation protein, DPP-6, DPP-8, DPP-9, quiescent cell proline dipeptidase, and DPP-4 $\beta$ (Busek et al 2004). This mandates careful evaluation of the selectivity of any agent used to inhibit DPP-4 activity and long-term safety studies (Lancas et al 2005). At least two human dipeptidyl-peptidases, DPP-8 and DPP-9, whose functions 
are still unknown, are structurally closely related to DPP-4. Acute toxicity in animal models was reported for at least one compound with strong DPP-8/DPP-9 inhibitory potency (Lancas et al 2005). In patients suffering from rheumatoid arthritis DPP-4 activity was inversely correlated with the severity of the disease (Busso et al 2005), indicating a role for DPP-4 in the control of immune regulation.

It is currently unknown whether 'selective' DPP-4 inhibitors used for the treatment of type 2 diabetes play a role in the control of immune function, transplantation biology or cancer cell growth (Dang and Morimoto 2002).

Currently, all data obtained using 'nonselective' and 'selective' DPP inhibitors need to be interpreted with caution. It is not known whether in vivo DPP-8 and DPP-9 are inhibited on administration of therapeutic doses of the DPP-4 inhibitors. However, to date no in vivo effects have been reported that point to a pharmacological impact of the inhibition of other peptidases.

Numerous endocrine peptides, chemokines, and neuropeptides such as bradykinin, endomorphin-2, growth hormone-releasing hormone, interleukin-2 and $-1 \beta$, prolactin, neuropeptide $\mathrm{Y}$ and substance $\mathrm{P}$ are putative but questionable physiological DPP-4 substrates (Drucker 2007). Levels of tissue DPP-4 are reduced in nasal tissue of people with chronic rhinosinusitis and DPP-4 inhibition seems to aggravate nasopharyngitis as could be observed in clinical studies. Therefore, it seems to be highly important to monitor DPP-4-treated patients for the development of inflammatory conditions, such as angioedema, rhinitis, and urticaria.

DPP4 also regulates migration of human cord blood $\mathrm{CD} 34^{+}$progenitor cells and the homing and engraftment of hematopoetic stem cells.

\section{Pharmacokinetic/-dynamic profile}

The current DPP-4 inhibitors display slow, tight-binding inhibition kinetics and are reversible competitive inhibitors of DPP-4 (Henness and Keam 2006; He et al 2007; LysengWilliamson 2007). Sitagliptin and vildagliptin have been explored in detail, both possess pharmacokinetic properties that support a once-daily dosing regimen. Clinically important pharmacokinetic/-dynamic parameters are summarized in Table 1.

Sitagliptin and vildagliptin are both orally active, rapidly absorbed, and mainly excreted by the kidneys. Whereas hepatic insufficiency does not seem to alter pharmacokinetics of these compounds, dose adjustments are required in patients with renal impairment, at least for sitagliptin
Table I Clinically important pharmacokinetic/-dynamic parameters of current DPP-4 inhibitors

\begin{tabular}{lll}
\hline & Sitagliptin & Vildagliptin \\
\hline $\begin{array}{l}\text { Selectivity for DPP-4 over DPP-8/9 } \\
\text { [-fold] }\end{array}$ & $>2600$ & $32-250$ \\
Absolute bioavailability [\%] & 87 & 85 \\
Time to reach maximum plasma & 2 & $1-2$ \\
concentration, $T_{\max }[\mathrm{hr}]$ & & \\
Volume of distribution [L] & 198 & 70.5 \\
Plasma protein binding [\%] & 38 & 9 \\
Terminal half life, $T_{1 / 2}[\mathrm{hr}]$ & 11.0 & $1.7^{\mathrm{a}}$ \\
Renal clearance $[\mathrm{L} / \mathrm{hr}]$ & 21 & 13 \\
Elimination in urine [\%] & 87 & 85 \\
Recommended dosage [mg/day] & 100 & 100 \\
\hline
\end{tabular}

Notes: a $100 \mathrm{mg}$ once daily ( 2.5 hrs with $100 \mathrm{mg}$ twice daily).

Abbreviations: DPP-4, dipeptidyl peptidase-4.

(Bergman et al 2007). Vildagliptin is not recommended for patients with severe liver problems (EMEA 2007b). It is recommended that renal function is assessed prior to the start of sitagliptin treatment. Studies in patients with renal insufficiency have not been reported to date on vildagliptin therapy. Both DPP-4 inhibitors should not be used for patients with moderate or severe kidney problems (EMEA 2007a, 2007b).

DPP-4 activity is inhibited by almost $100 \%$ at 15 to 30 min after oral ingestion, and more than $80 \%$ inhibition lasts for more than 16 hours due to the initial phase of rapid binding followed by a slow phase of very tight binding kinetics (Ahrén et al 2004a).

The pharmacokinetics of vildagliptin and sitagliptin do not seem to be affected by age, gender, ethnicity, or body mass index. Co-administration of DPP-4 inhibitors with several other antidiabetic agents and other drugs including digoxin, simvastatin, and warfarin has so far not uncovered any relevant drug interactions.

The recommended dosage of sitagliptin is $100 \mathrm{mg}$ orally once daily, either as monotherapy or in antidiabetic combination therapy, taken with or without food (EMEA 2007a). The recommended dose of vildagliptin is $100 \mathrm{mg}$ when used with metformin or a thiazolidinedione or $50 \mathrm{mg}$ in combination with a sulphonylurea (EMEA 2007b).

\section{Efficacy studies Search strategy}

We identified studies by a systematic literature search of MEDLINE, EMBASE, and the Cochrane Library for randomized controlled clinical trials, systematic reviews, meta-analyses and health-technology assessment reports 
of DPP-4 inhibitor therapy in adults with type 2 diabetes mellitus. Search terms included "sitagliptin", "vildagliptin", “saxagliptin”, “gliptin”, “incretin”, “dipeptidyl peptidase”, "DPP”, "LAF237", and "MK-0431". The title and abstract of studies identified in the search were scanned by two reviewers to exclude any hits that clearly were irrelevant. The full text of the remaining articles was read to determine whether it contained information on the topic of interest. The reference lists of the remaining articles as well as all reviews on the topic were also reviewed for additional pertinent studies. Abstracts of research presented at related conferences were also searched.

We followed the QUOROM (quality of reporting of meta-analyses) guidelines (Moher et al 1999) and the methodology recommended by the Cochrane Handbook for Systematic Reviews of Interventions (Higgins and Green 2006) for reporting our meta-analysis methods and results.

\section{Selection criteria}

We included studies of at least 12 weeks' duration because such studies would give an adequate assessment of change in glycemic efficacy, as glycosylated hemoglobin $\mathrm{A}_{1 \mathrm{c}}$ reflects glycemia during the previous three months (Goldstein et al 2004). When there were multiple publications or companion papers from the same population we tried to maximize yield of information by simultaneous evaluation of all relevant study data. Any discrepancies were resolved by consensus between two independent reviewers or with the help of a third author via referencing the original article.

\section{Data extraction and risk of bias assessment}

Two reviewers abstracted data independently. Participant baseline characteristics of the included studies were extracted. We obtained data for glycemic efficacy from change from baseline to study endpoint in A1c. Data on change in body weight were also extracted. To evaluate safety, we extracted data on hypoglycemic episodes and all reported adverse events. Description of allocation concealment, intention- to-treat analysis, and attrition rates were mainly used to evaluate risk of bias.

\section{Data synthesis and analysis}

The primary measure for glycemic efficacy was the treatment group difference in A1c change from baseline to study endpoint. For safety, we analyzed the number of participants reporting adverse events. For continuous variables (A1c, body weight), we calculated weighted mean differences and 95\% confidence intervals (CIs) for change from baseline in DPP-4 inhibitors versus control (placebo or hypoglycemic agent) groups. For dichotomous variables (adverse events), we calculated the odds ratios and 95\% CIs for DPP-4 inhibitors versus control. If data from more than two trials were available, we combined data from trials and explored heterogeneity between comparable trials with prespecified subgroup analyses by type of comparator group (placebo vs hypoglycemic agent) and duration of intervention (12 versus longer than 12 weeks), for each compound separately. For sitagliptin and vildagliptin mainly data on the recommended $100 \mathrm{mg} /$ day dosage were used.

Meta-analyses were performed by means of a randomeffects model. Many studies reported differences in the mean changes and the corresponding 95\% CIs (or standard errors) between comparison groups. Standard errors were converted to standard deviations by multiplying standard errors of means by the square-root of the sample size: $\mathrm{SD}=\mathrm{SE} \times \sqrt{ } \mathrm{N}$ (Higgins and Green 2006). Confidence intervals for mean changes within treatment groups were also converted to standard deviations. If the sample size was large, the standard deviation for each group was obtained by dividing the length of the $95 \%$ confidence interval by 3.92 , and then multiplied by the square root of the sample size: $\mathrm{SD}=\sqrt{ } \mathrm{N} \times(($ upper $\mathrm{CI}$ limit - lower CI limit $) / 3.92)$ (Higgins and Green 2006).

In the event of substantial clinical or methodological or statistical heterogeneity, study results were not combined by means of meta-analysis. Heterogeneity was identified by visual inspection of the forest plots, by using a standard $\chi^{2}$-test and a significance level of $\alpha=0.1$, in view of the low power of such tests. Heterogeneity was specifically examined with $\mathrm{I}^{2}$ (Higgins and Thompson 2002), where $\mathrm{I}^{2}$ values of $50 \%$ and more indicate a substantial level of heterogeneity (Higgins et al 2003). When heterogeneity was found, we attempted to determine potential reasons for it by examining individual study characteristics and those of subgroups of the main body of evidence.

\section{Search results and study characteristics}

The initial search revealed 886 abstracts, out of these 85 full publications were evaluated. After extraction of reviews and exclusion of studies ( $\mathrm{n}=13$, main reason was duration of trial less than 12 weeks) 22 publications remained, 12 reported on vildagliptin therapy (Ahrén et al 2004b; Ristic et al 2005; Mimori et al 2006; Pratley et al 2006; Bosi et al 
Table 2 Main baseline characteristics (mean values across all study arms) of randomized controlled trials of DPP-4 inhibitors

\begin{tabular}{|c|c|c|c|c|}
\hline & \multicolumn{2}{|l|}{ Sitagliptin } & \multicolumn{2}{|l|}{ Vildagliptin } \\
\hline & Intervention $^{\mathrm{a}}$ & Control $^{\mathrm{b}}$ & Intervention ${ }^{a}$ & Control ${ }^{b}$ \\
\hline Female sex [\%] & 49.2 & 47.7 & 45.9 & 45.2 \\
\hline Age $[y r s]$ & 55.0 & 54.2 & 54.4 & 54.2 \\
\hline Ethnic group, white participants [\%] & 68.8 & 59.1 & 67.5 & 67.2 \\
\hline Duration of disease [yrs] & 4.5 & 4.7 & 3.3 & 4.4 \\
\hline Body mass index $\left[\mathrm{kg} / \mathrm{m}^{2}\right]$ & 31.5 & 31.7 & 31.4 & 31.8 \\
\hline Pharmaco-naïve patients ${ }^{c}[\%]$ & 39.9 & 45.4 & d & d \\
\hline $\mathrm{HbA}_{\mathrm{lc}}[\%]$ & 8.0 & 8.5 & 8.2 & 8.4 \\
\hline
\end{tabular}

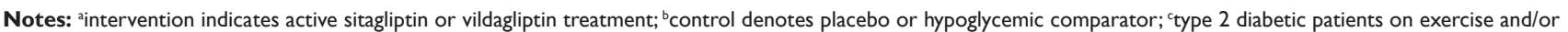

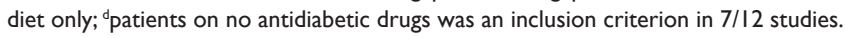

Abbreviations: DPP-4, dipeptidyl peptidase-4; $\mathrm{HbA}_{1 \mathrm{c}}$, hemoglobin Alc.

2007; Dejager et al 2007; Fonseca et al 2007; Garber et al 2007; Pi-Sunyer et al 2007; Rosenstock et al 2007a, 2007b; Schweizer et al 2007) in type 2 diabetes and 10 on sitagliptin treatment (Aschner et al 2006; Charbonnel et al 2006; Nonaka et al 2006; Raz et al 2006; Rosenstock et al 2006; Goldstein et al 2007; Hanefeld et al 2007; Hermansen et al 2007; Nauck et al 2007; Scott et al 2007).

Most studies were performed in a multicenter design, mainly in North America and Europe, with participating countries ranging from 1 to 34 (mean 16) for sitagliptin and 1 to 11 (mean 5) for vildagliptin, respectively.

The main baseline characteristics for the 22 included trials are summarized in Table 2.

The median duration of sitagliptin/vildagliptin trials was 24 weeks. There was one study in each DPP-4 inhibitor class which investigated the primary randomized patient group after one year of treatment.

Six (five) study arms directly compared sitagliptin (vildagliptin) with placebo, two (three) with another hypoglycemic agent and five (five) contrasted various combination therapies.

Gender ratio was roughly balanced between the sitagliptin/vildagliptin intervention/control groups and also comparing the two agents with each other. Participants were mostly white, obese, around 55 years of age with a duration of diabetes between three to five years. A large proportion across all trials consisted of participants who were treated by diet and/or exercise only. Baseline A1c was slightly worse in the sitagliptin/vildagliptin control groups $(+0.5 \% /+0.2 \%$, respectively). No publication revealed data on co-morbidities.

\section{Risk of bias}

All studies included a control group in a double-blind design, besides one vildagliptin trial involving insulin, which had an open-label design (Fonseca et al 2007). One sitagliptin (Nauck et al 2007) and two vildagliptin studies (Rosenstock et al 2007a; Schweizer et al 2007) tested for noninferiority. One vildagliptin trial described power calculation (Schweizer et al 2007).

Key quality criteria of risk of bias reduction are outlined in Table 3.

No study clearly described method of randomization or concealment of allocation. Most publications mentioned intention-to-treat analysis with last-observation carried forward for missing primary efficacy endpoints.

The total number of randomized type 2 diabetes participants in the included sitagliptin/vildagliptin studies was $6028 / 5239$. Mean attrition rates were rather high, ranging from $16 \%$ to $17 \%$, with high withdrawal rates in the placebo groups due to loss of glycemic control. All studies were funded by pharmaceutical companies with a considerable number of individuals from the industries named as authors in the publications.

Table 3 Key indicators for reduction of risk of bias in randomized controlled trials of DPP-4 inhibitor therapy

\begin{tabular}{lll}
\hline & Sitagliptin & Vildagliptin \\
\hline $\begin{array}{l}\text { Method of randomization } \\
\text { described [n studies] }\end{array}$ & $0 / 12$ & $0 / 12$ \\
$\begin{array}{l}\text { Concealment of allocation } \\
\text { described [n studies] }\end{array}$ & $0 / 12$ & $0 / 12$ \\
$\begin{array}{l}\text { Intention-to-treat analysis } \\
\text { mentioned [n studies] }\end{array}$ & $9 / 10$ & $1 \mathrm{I} / 12$ \\
$\begin{array}{l}\text { Missing data: imputation } \\
\text { method used [n studies] }\end{array}$ & $9 / 10$ & $1 \mathrm{I} / 12$ \\
$\begin{array}{l}\text { No. of randomized patients } \\
\text { [intervention/control] }\end{array}$ & $3691 / 2337$ & $3604 / 1635$ \\
\begin{tabular}{l} 
Mean discontinuation rate [\%] \\
\hline
\end{tabular} & 15.8 & 17.2 \\
\hline
\end{tabular}

Abbreviations: DPP $=4$, dipeptidyl peptidase- 4 . 


\section{Outcomes}

Unfortunately, so far no study investigated patient-oriented parameters like diabetic complications, health-related quality of life and treatment satisfaction.

All trials evaluated A1c change from baseline to (imputed) endpoint as the primary efficacy parameter. Secondary outcomes (specified as such in $16 / 22$ publications) varied, but mostly included fasting plasma glucose, fasting lipids, body weight and investigations of $\beta$-cell function and insulin sensitivity. Safety evaluation encompassed adverse experiences including hypoglycemic episodes and pre-specified gastro-intestinal events such as abdominal pain, nausea, vomiting and diarrhea. Furthermore, physical examinations, evaluation of vital signs, electrocardiograms and safety laboratory assessments were mentioned in all publications.

Figure 1.1 shows the effects of vildagliptin treatment on A1c mean changes in the course of the study. The first panel provides an overview of all study arms for illustrating purposes only. Compared to placebo, vildagliptin resulted in a significant reduction of A1c but with a substantial amount of heterogeneity $\left(\mathrm{I}^{2}=93.2 \%\right)$. Elimination of the study by Mimori and colleagues (2006), investigating Japanese patients only, resulted in a sizable reduction of heterogeneity $\left(\mathrm{I}^{2}=25.4 \%\right)$ with a more stable pooled effect size of $-0.6 \% \mathrm{~A} 1 \mathrm{c}$ reduction $(95 \% \mathrm{CI}-0.8$ to -0.4 , $\mathrm{P}<0.00001)$ in favor of vildagliptin. Contrasted to another single hypoglycemic agent, vildagliptin demonstrated less lowering of A1c (mean difference $0.3 \%, 95 \%$ CI 0.1 to $0.5, \mathrm{P}=0.0002$ ), non-inferiority to metformin was not established. When combined with other antidiabetic compounds, vildagliptin lead to an additional lowering of A1c $(-0.7 \%, 95 \% \mathrm{CI}-0.9$ to $-0.4, \mathrm{P}<0.00001)$. The effects of vildagliptin on metabolic control did not decrease if the effects of 12 weeks' versus 24 weeks' treatment in comparison to placebo were analyzed.

Figure 2.1.1 reveals the effects of sitagliptin treatment on A1c mean changes. The first panel provides an overview of all study arms for illustrating purposes only. Compared with placebo, sitagliptin resulted in a significant reduction of A1c $(-0.7 \%, 95 \% \mathrm{CI}-0.9 \%$ to $-0.6 \%, \mathrm{P}<0.00001)$. Contrasted to another single hypoglycemic agent, sitagliptin was inferior (mean difference $0.3 \%, 95 \%$ CI 0.1 to $0.6, \mathrm{P}=0.007$ ). Sitagliptin combination therapy lead to additional lowering of A1c but heterogeneity was substantial. The effects of sitagliptin on metabolic control did also not diminish if the A1c of 12 weeks' versus 24 weeks' treatment and against placebo were compared.

\section{Safety and tolerability}

Severe hypoglycemia as defined by requiring third party assistance was not reported in patients taking DPP-4 inhibitors. There were no statistically significant differences (data not shown) in hypoglycemic episodes between sitagliptin/vildagliptin and comparator groups. Also, risk of gastrointestinal adverse effects was comparable to placebo. Headache was reported more often with DPP-4 inhibitors, especially following vildagliptin therapy (data not shown). Overall, sitagliptin and vildagliptin were well tolerated.

Figures 1.2.1 and 2.2.1 display attrition rates due to adverse events, number of serious adverse events, and allcause infections.

Withdrawals due to adverse effects of DPP-4 inhibitor treatment were not significantly raised in comparison to control groups (odds ratio for vildagliptin $0.85,95 \% \mathrm{CI}$ 0.58 to 1.25 ; odds ratio for sitagliptin $0.92,95 \%$ CI 0,69 to 1.24$)$.

Also, serious adverse events were not observed more often following DPP-4 inhibition (odds ratio for vildagliptin $0.86,95 \%$ CI 0.51 to 1.46 ; odds ratio for sitagliptin 1.07 , $95 \%$ CI 0.82 to 1.40 ).

However, after combining studies with available data, there was an increased risk of all-cause infections (nasopharyngitis, sinusitis, upper respiratory tract infection, urinary tract infection, viral infection) for sitagliptin (odds ratio $1.34,95 \%$ CI 1.10 to $1.64, \mathrm{P}=0.004$ ), but not for vildagliptin.

Figures 1.3.1 and 2.3.1 show the effects of DPP-4 inhibition on body weight. The first panel provides an overview of all study arms for illustrating purposes only.

Fifteen studies provided data on weight changes. Compared to placebo, a small increase in weight was noted after DPP-4 inhibitor treatment (vildagliptin $+0.8 \mathrm{~kg}, 95 \%$ CI 0.2 to $1.3, \mathrm{P}=0.009$; sitagliptin $+0.7 \mathrm{~kg}, 95 \%$ CI 0.2 to $1.2, \mathrm{P}=0.008)$. Comparison of DPP-4 inhibitors versus all hypoglycemic agents did not indicate significant differences between comparators for pooled effect sizes. Taking into account different classes of antidiabetic agents, a favorable weight profile was noted when vildagliptin was compared to pioglitazone as well as after sitagliptin/metformin versus glipizide/metformin combination therapy.

\section{Conclusions and place in therapy}

Overall, the magnitude of the A1c improvements with DPP-4 inhibitors versus placebo was $0.7 \%$ but could not be replicated in direct comparison to monotherapy with other hypoglycemic agents $(0.3 \% \mathrm{~A} 1 \mathrm{c}$ reduction in favor of 


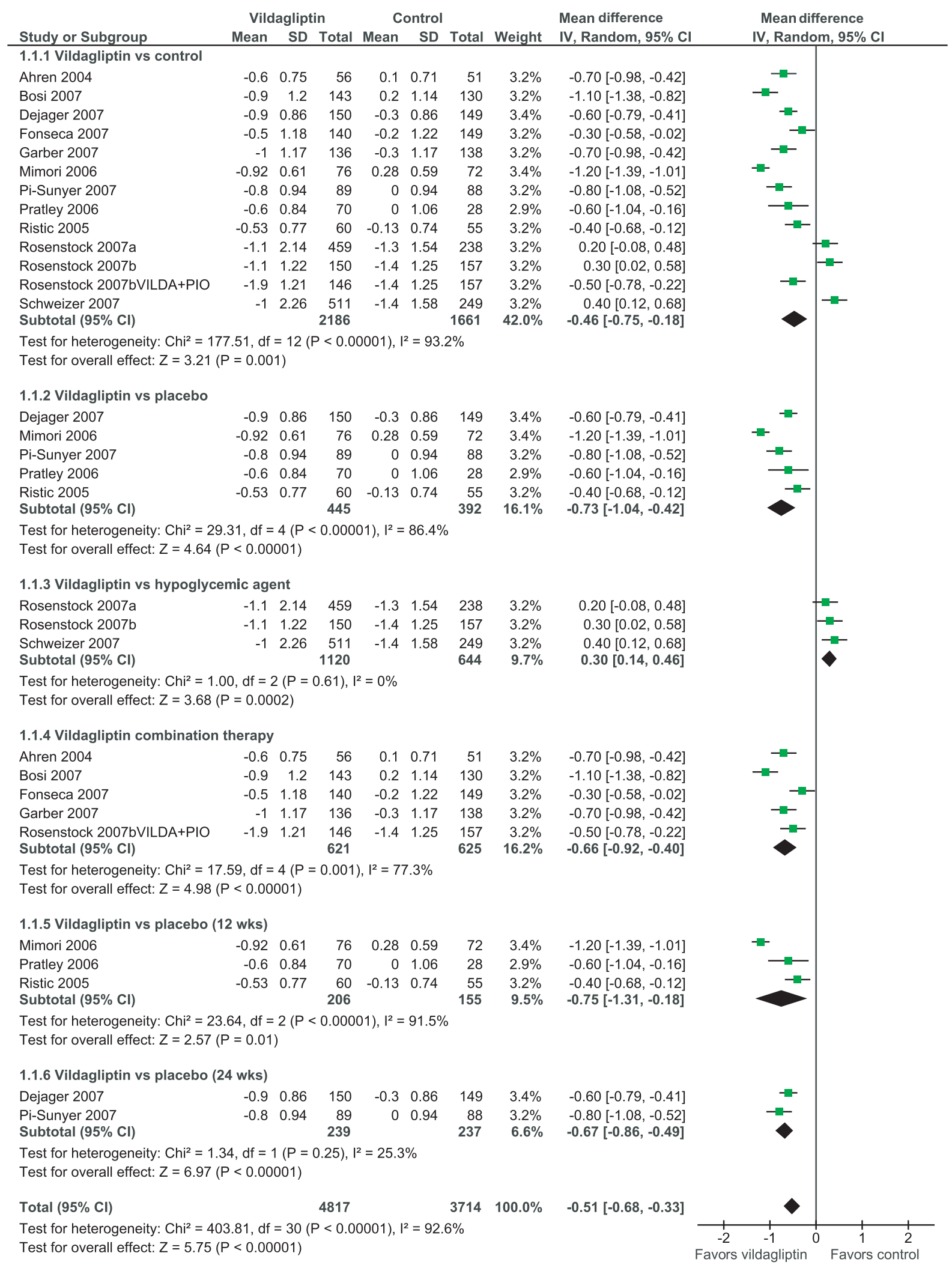

Figure I.I Mean $\mathrm{HbA}_{\mathrm{lc}}$ changes [\%] from baseline to (imputed) endpoint in vildagliptin randomised controlled trials. Weighted mean differences by means of random-effects model (inverse varicance (IV) method) showing $95 \%$ confidence intervals $(\mathrm{Cl})$ for single studies and pooled effect sizes. $\mathrm{I}^{2}$ describes the percentage of total variation across studies due to heterogeneity.

Abbreviations: $\mathrm{HbA}_{\mathrm{Ic}}$, hemoglobin Alc. 


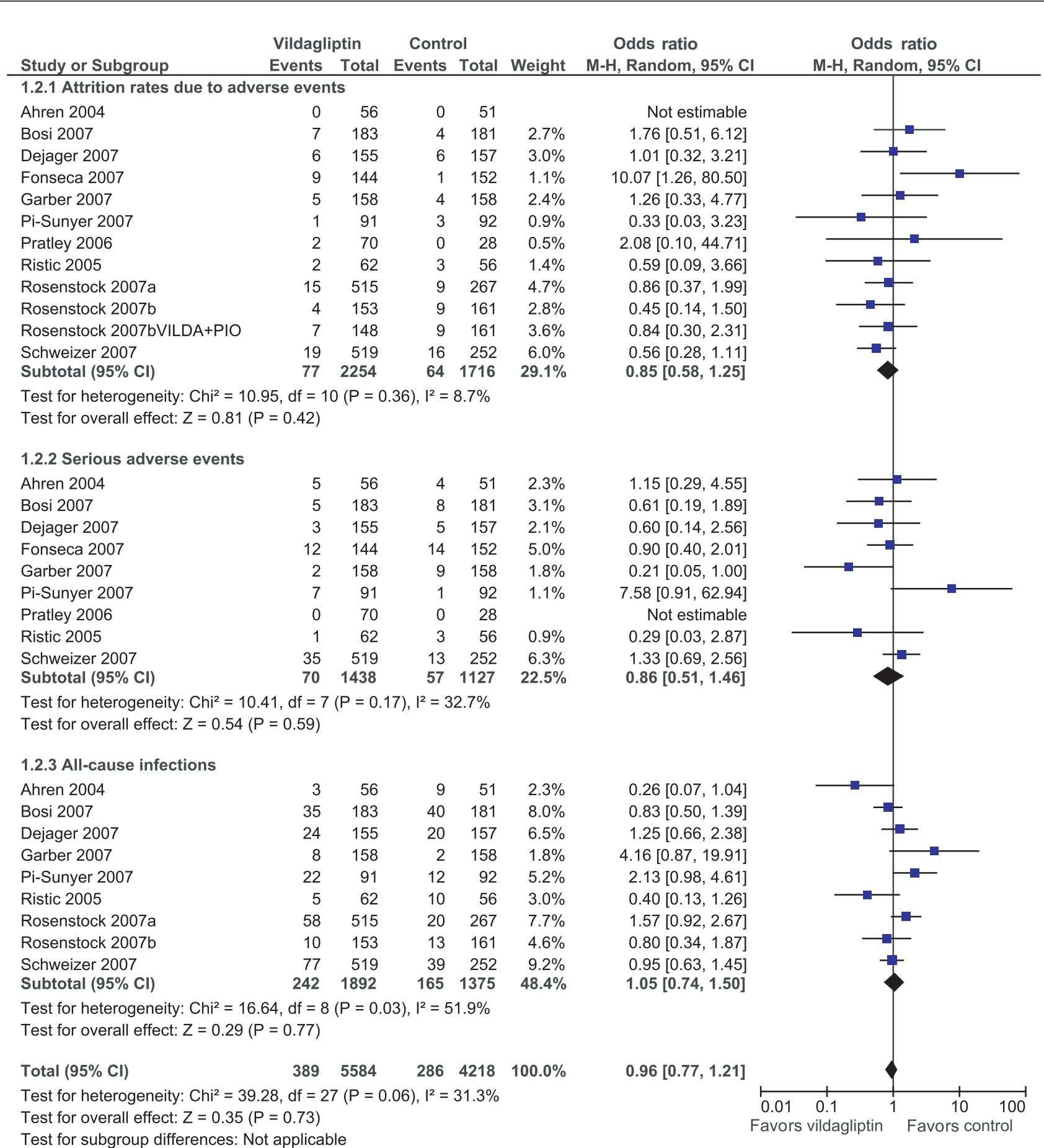

Figure I.2 Attrition rates due to adverse events, number of serious adverse events and all-cause infections in vildagliptin randomized controlled trials. Odds ratios by means of random-effects model (Mantel-Haenszel $(\mathrm{M}-\mathrm{H})$ method) showing $95 \%$ confidence intervals $(\mathrm{Cl})$ for single studies and pooled effect sizes. $\mathrm{I}^{2}$ describes the percentage of total variation across studies due to heterogeneity.

controls). Compared with placebo, a small increase in weight was noted ( 0.7 to $0.8 \mathrm{~kg}$ ). The overall risk profile was low, however an increased relative risk of $34 \%$ for all-cause infections after sitagliptin treatment was observed. Although, the risk of increased infection appears small, its consequences when translated into clinical practice with millions of type 2 diabetic patients treated could be considerable (Amori et al 2007).

The low rate of hypoglycemic events seen across studies confirms the glucose-dependent actions of the DPP-4 inhibitors (Drucker and Nauck 2006). However, hypoglycemia is still possible, especially in combination therapies. All these 


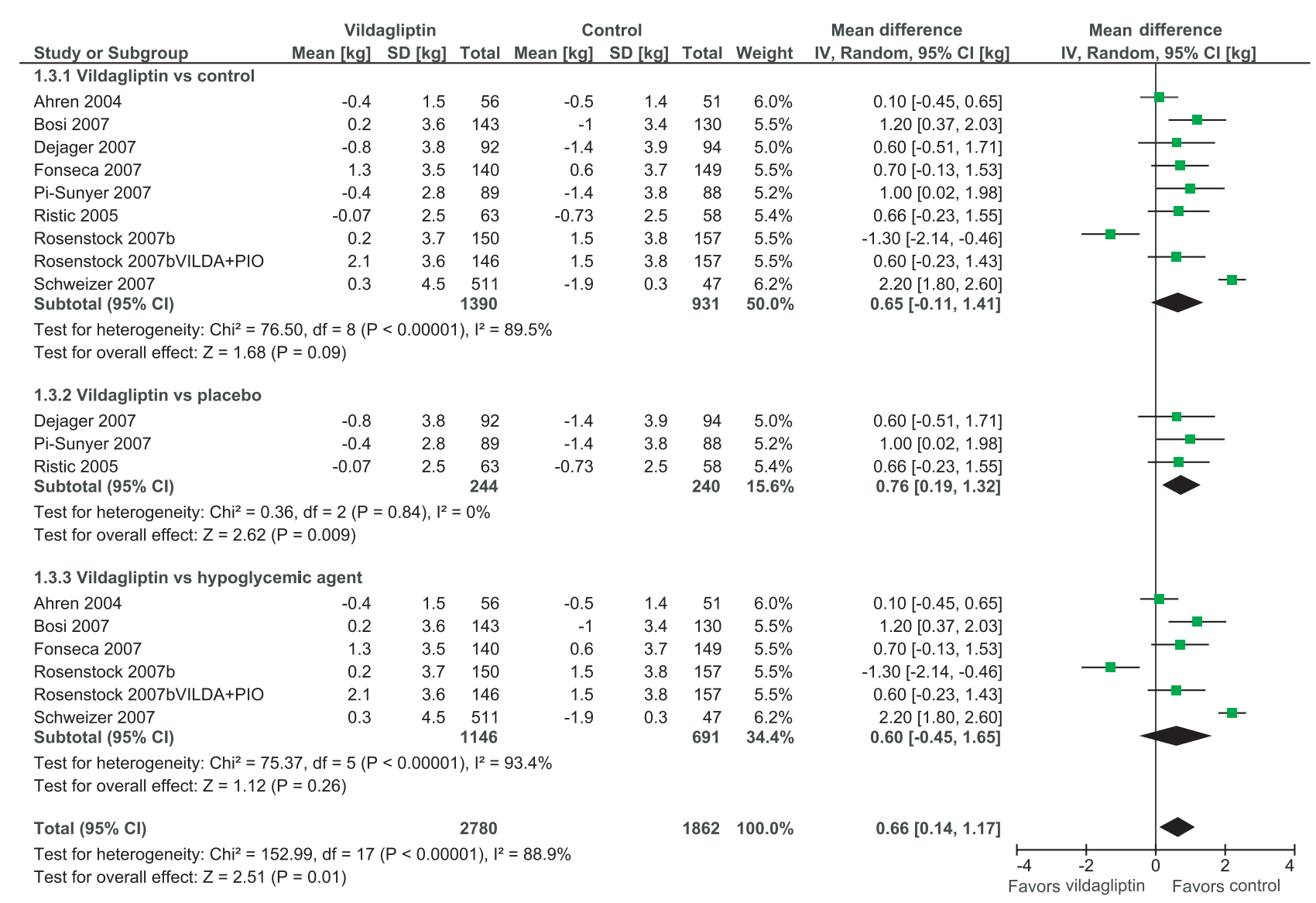

Figure I.3 Mean body weight changes [kg] in vildagliptin randomised controlled trials. Weighted mean differences by means of random-effects model (inverse varicance (IV) method) showing $95 \%$ confidence intervals $(\mathrm{Cl})$ for single studies and pooled effect sizes. $\mathrm{I}^{2}$ describes the percentage of total variation across studies due to heterogeneity.

results have to be interpreted with caution due to the relatively high risk of bias with high attrition rates and poor reporting of key quality indicators.

Traditional treatments for type 2 diabetes do not seem to address the progressive decline in $\beta$-cell function and patients continue to advance in their disease state. DPP-4 inhibitors could theoretically preserve and even reverse the progressive loss of insulin secretory capacity, although long-term studies in type 2 diabetic patients will be required to demonstrate this change.

Currently, there are no head-to-head studies comparing sitagliptin and vildagliptin, and caution must therefore be exercised in judging relative efficacy. Theoretically, DPP-4 inhibition seems to have the strongest potential in early stages of type 2 diabetes because of the impaired GLP-1 secretion in type 2 diabetes, together with both poor insulin secretion and sensitivity as well as partial insensitivity to GLP-1.

However, there is a considerable risk of potential adverse effects of DPP-4 inhibitors, especially on the immune system.
It is disturbing to note that in all our included published randomized controlled trials of sitagliptin/vildagliptin only routine laboratory safety measurements were reported. Why were elaborated laboratory measurements not performed or reported? The best chance to do so was under well-controlled early stage efficacy studies. Moreover, due to the important association of type 2 diabetes with cardiovascular disease any new antihypoglycemic agent for type 2 diabetes should be investigated for its effects on cardiovascular risk and outcomes.

As a consequence of recently discovered complications with another antidiabetic compound (Rosen 2007), it was discussed that regulatory authorities should change their way of approval of antidiabetic drugs which still focuses on glucose-lowering potencies of new medications (Solomon and Winkelmayer 2007) instead on patient-important outcomes (Montori et al 2007).

Summarizing our findings, DPP-4 inhibitors present a desirable additional choice and possible alternative treatment option to presently available antidiabetic agents 


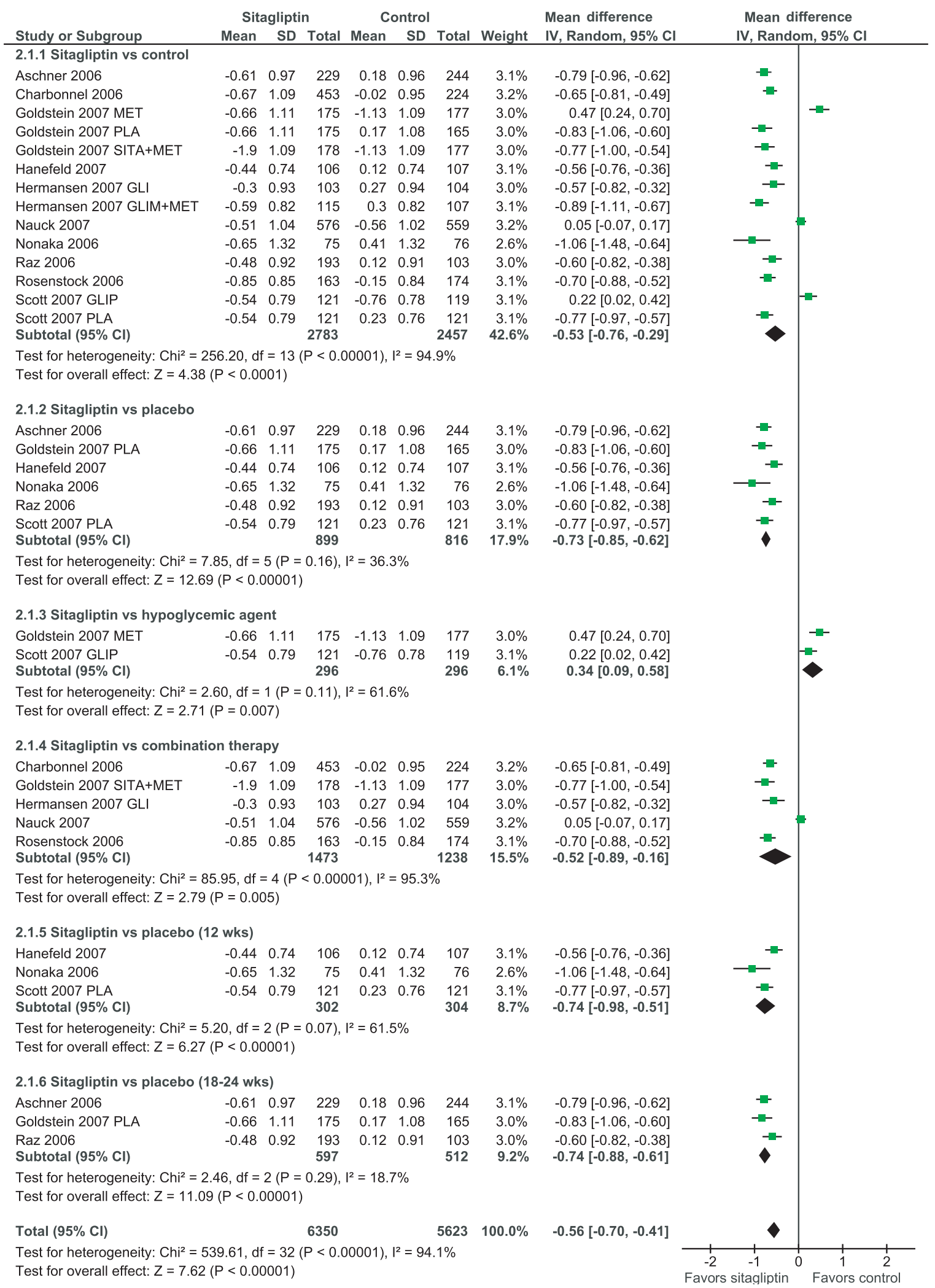

Figure 2.I Mean $\mathrm{HbA}_{\mathrm{Ic}}$ changes [\%] from baseline to (imputed) endpoint in sitagliptin randomised controlled trials. Weighted mean differences by means of random-effects model (inverse varicance (IV) method) showing $95 \%$ confidence intervals ( $\mathrm{Cl}$ ) for single studies and pooled effect sizes. $I^{2}$ describes the percentage of total variation across studies due to heterogeneity.

Abbreviations: $\mathrm{HbA}_{\mathrm{Ic}}$, hemoglobin Alc. 


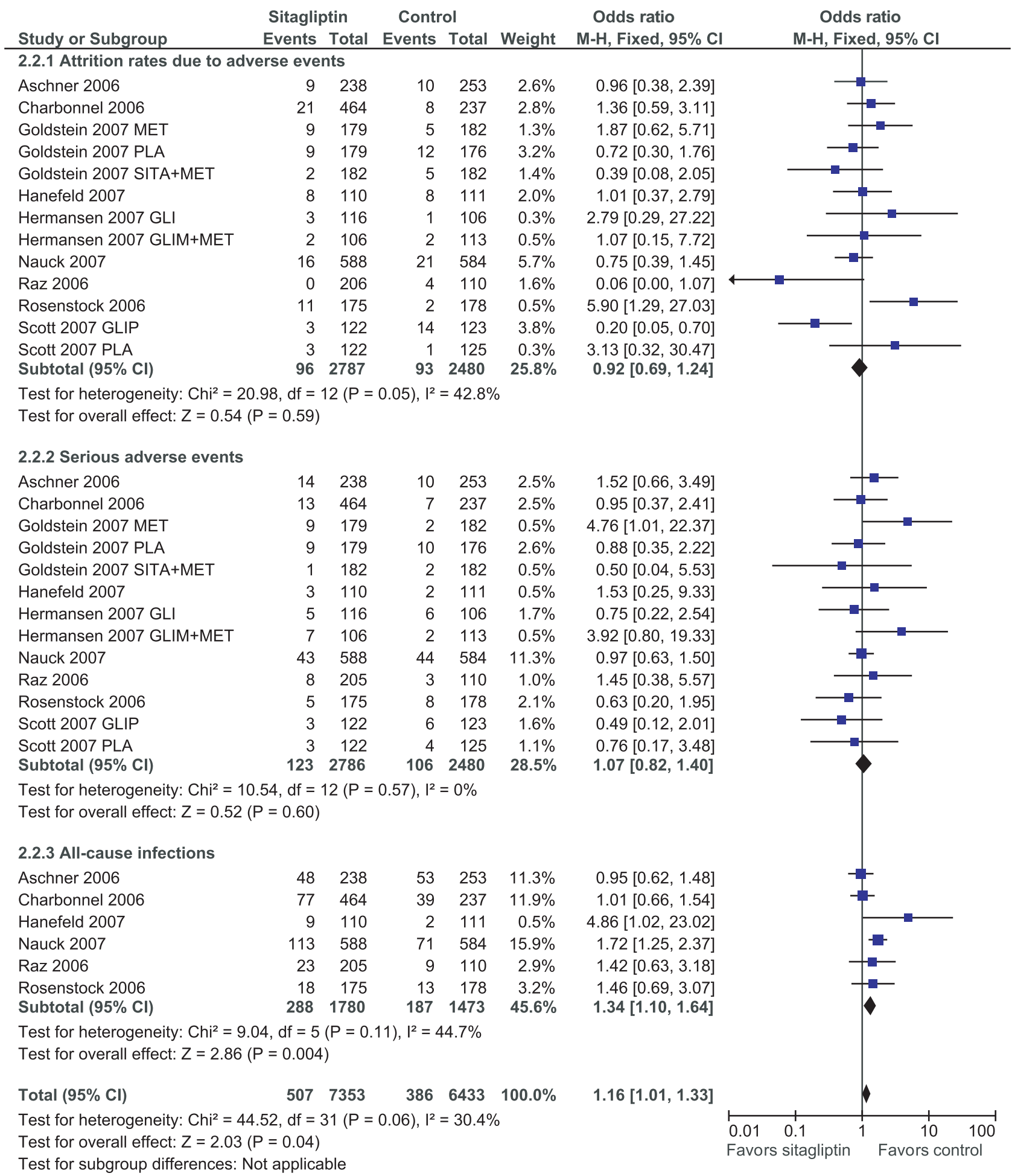

Figure 2.2 Attrition rates due to adverse events, number of serious adverse events and all-cause infections in sitagliptin randomised controlled trials. Odds ratios by means of random-effects model (Mantel-Haenszel $(\mathrm{M}-\mathrm{H})$ method) showing $95 \%$ confidence intervals $(\mathrm{Cl})$ for single studies and pooled effect sizes. $I^{2}$ describes the percentage of total variation across studies due to heterogeneity. 


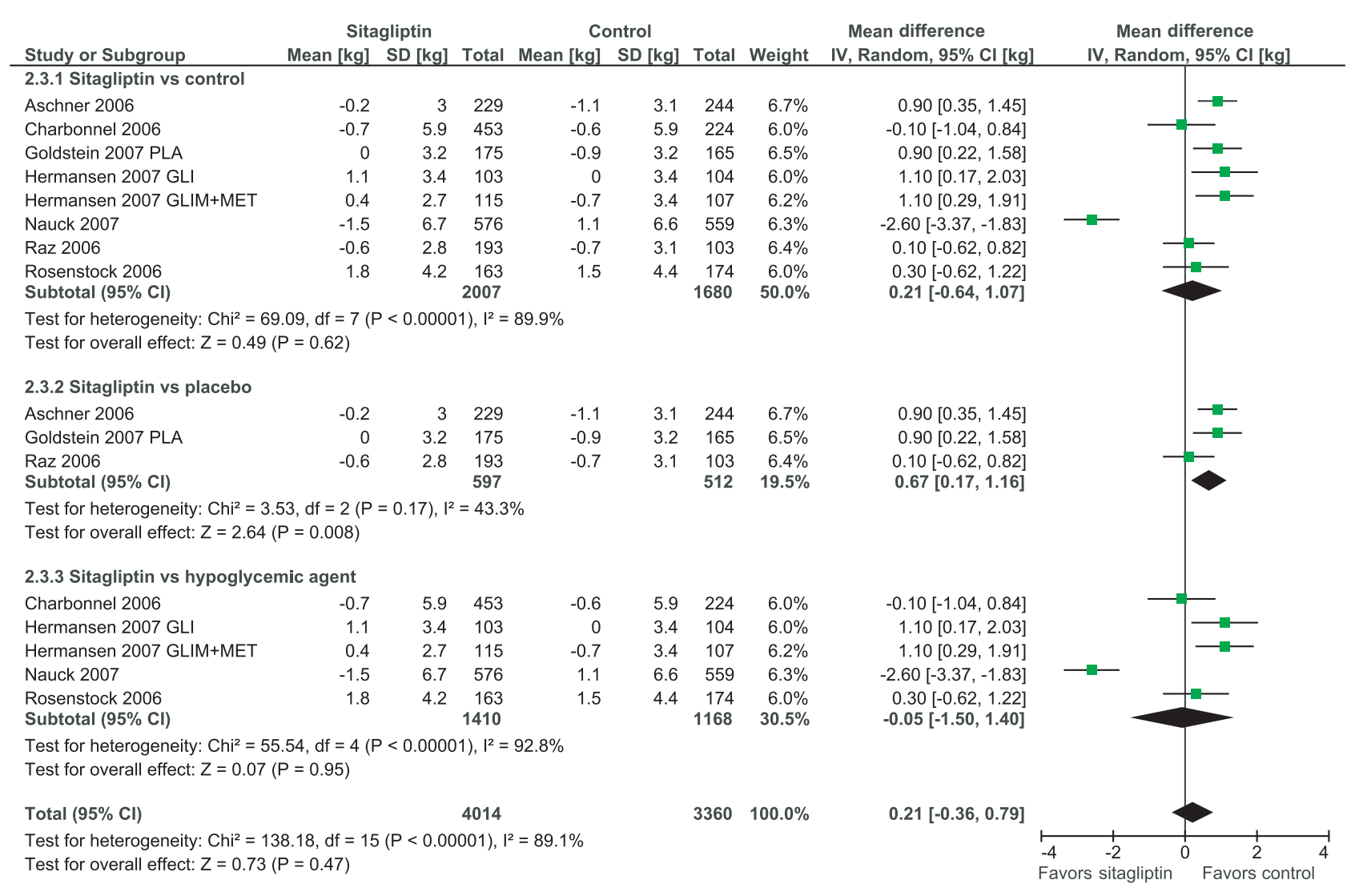

Figure 2.3 Mean body weight changes [kg] in sitagliptin randomised controlled trials. Weighted mean differences by means of random-effects model (inverse varicance (IV) method) showing $95 \%$ confidence intervals $(\mathrm{Cl})$ for single studies and pooled effect sizes. $\mathrm{I}^{2}$ describes the percentage of total variation across studies due to heterogeneity.

in type 2 diabetes, but due to the still unknown benefit-risk ratio their use should currently be restricted to individual patients until long-term safety and efficacy data are reported.

\section{References}

Ahrén B. 2004. Sensory nerves contribute to insulin secretion by glucagonlike peptide-1 (GLP-1) in mice. Am J Physiol, 286:R269-72.

Ahrén B, Landin-Olsson M, Jansson PA, et al. 2004a. Inhibition of dipeptidyl peptidase-4 reduces glycemia, sustains insulin levels and reduces glucagon levels in type 2 diabetes. J Clin Endocrinol Metab, 89:2078-84.

Ahrén B, Gomis R, Standl E, et al. 2004b. Twelve- and 52-week efficacy of the dipeptidyl peptidase IV inhibitor LAF237 in metformin-treated patients with type 2 diabetes. Diabetes Care, 27:2874-80.

Amori RE, Lau J, Pittas AG. 2007. Efficacy and safety of incretin therapy in type 2 diabetes. JAMA, 298:194-206.

Aschner P, Kipnes MS, Lunceford JK, et al. 2006. Effect of the dipeptidyl peptidase-4 inhibitor sitagliptin as monotherapy on glycemic control in patients with type 2 diabetes. Diabetes Care, 29:2632-7.

Bergman AJ, Cote J, Yi B, et al. 2007. Effect of renal insufficiency on the pharmakokinetics of sitagliptin, a dipeptidyl peptidase-4 inhibitor. Diabetes Care, 30:1862-4.

Bloomgarden ZT. 2007. Insulin resistance, dyslipidemia, and cardiovascular disease. Diabetes Care, 30:2164-70.

Bosi E, Camisasca RP, Collober C, et al. 2007. Effects of vildagliptin on glucose control over 24 weeks in patients with type 2 diabetes inadequately controlled with metformin. Diabetes Care, $30: 890-5$.
Busek P, Malik R, Sedo A. 2004. Dipeptidyl peptidase IV activity and/or structure homologues (DASH) and their substrates in cancer. Int $J$ Biochem Cell Biol, 36:408-21.

Busso N, Wagtmann N, Herling C, et al. 2005. Circulating CD26 is negatively associated with inflammation in human and experimental arthritis. Am J Pathol, 166:433-42.

Charbonnel B, Karasik A, Liu J, et al. 2006. Efficacy and safety of the dipeptidyl peptidase-4 inhibitor sitagliptin added to ongoing metformin therapy in patients with type 2 diabetes inadequately controlled with metformin alone. Diabetes Care, 29:2638-43.

Cleland JGF, Atkin SL. 2007. Thiazolidinediones, deadly sins, surrogates, and elephants. Lancet, 370:1103-4.

Creutzfeldt W. 2005. The (pre) history of the incretin concept. Regul Pept, 128:87-91.

Dang NH, Morimoto C. 2002. CD26: an expanding role in immune regulation and cancer. Histol Histopathol, 17:1213-26.

De Meester I, Durinx C, Bal G, et al. 2000. Natural substrates of dipeptidyl peptidase IV. Adv Exp Med Biol, 477:67-87.

De Meester I, Lambeir AM, Proost P, et al. 2003. Dipeptidyl peptidase IV substrates: an update on in vitro peptide hydrolysis by human DPPIV. Adv Exp Med Biol, 524:3-17.

Deacon CF, Nauck MA, Toft-Nielsen M, et al. 1995. Both subcutaneously and intravenously administered glucagon-like peptide 1 are rapidly degraded from the NH2-terminus in type 2-diabetic patients and in healthy subjects. Diabetes, 44:1126-31.

Deacon CF. 2004. Circulation and degradation of GIP and GLP-1. Horm Metab Res, 36:761-5.

Deacon CF. 2005. What do we know about the secretion and degradation of incretin hormones? Regul Pept, 128:117-24.

DeFronzo RA, Bonadonna RC, Ferrannini E. 1992. Pathogenesis of NIDDM: a balanced overview. Diabetes Care, 15:318-68. 
Dejager S, Razac S, Foley JE, et al. 2007. Vildagliptin in drug-naive patients with type 2 diabetes: a 24-week, double-blind, randomized, placebocontrolled, multiple-dose study. Horm Metab Res, 39:218-23.

Drucker DJ, Philippe J, Mojsov S, et al. 1987. Glucagon-like peptide I stimulates insulin gene expression and increases cyclic AMP levels in a rat islet cell line. Proc Natl Acad Sci USA, 84:3434-8.

Drucker DJ, Nauck MA. 2006. The incretin system: glucagon-like peptide-1 receptor agonists and dipeptidyl peptidase- 4 inhibitors in type 2 diabetes. Lancet, 368:1696-705.

Drucker DJ. 2007. Dipeptidyl peptidase-4 inhibition and the treatment of type 2 diabetes: preclinical biology and mechanisms of action. Diabetes Care, 30:1335-43.

Efendic S, Portwood N. 2004. Overview of incretin hormones. Horm Metab Res, 36:742-6.

[EMEA] European Medicines Agency. 2007a. European public assessment report (EPAR) - Januvia [online]. Accessed November 15, 2007. URL: http://www.emea.europa.eu.

[EMEA] European Medicines Agency. 2007b. European public assessment report (EPAR) - Galvus [online]. Accessed November 15, 2007. URL http://www.emea.europa.eu.

Ewart RM. 2001. The case against aggressive treatment of type 2 diabetes: critique of the UK prospective diabetes study. BMJ, 323:854-8.

Farilla L, Bulotta A, Hirshberg B, et al. 2003. Glucagon-like peptide 1 inhibits cell apoptosis and improves glucose responsiveness of freshly isolated human islets. Endocrinology, 144:5149-58.

Fonseca V, Schweizer A, Albrecht D, et al. 2007. Addition of vildagliptin to insulin improves glycaemic control in type 2 diabetes. Diabetologia, 50:1148-55.

Ford ES. 2005. Risks for all-cause mortality, cardiovascular disease, and diabetes associated with the metabolic syndrome: a summary of the evidence. Diabetes Care, 28:1769-78.

Freemantle N, Calvert M, Wood J, et al. 2003. Composite outcomes in randomized trials: greater precision but with greater uncertainty? JAMA, 289:2554-9.

Garber AJ, Schweizer A, Baron MA, et al. 2007. Vildagliptin in combination with pioglitazone improves glycaemic control in patients with type 2 diabetes failing thiazolidinedione monotherapy: a randomized, placebo-controlled study. Diabetes Obes Metab, 9:166-74.

Goldstein DE, Little RR, Lorenz RA, et al. 2004. Tests of glycemia in diabetes. Diabetes Care, 27:1761-73.

Goldstein BJ, Feinglos MN, Lunceford JK, et al. 2007. Effect of initial combination therapy with sitagliptin, a dipeptidyl peptidase-4 inhibitor, and metformin on glycemic control in patients with type 2 diabetes. Diabetes Care, 30:1979-87.

Gromada J, Bokvist K, Ding WG, et al. 1998. Glucagon-like peptide 1 (7-36) amide stimulates exocytosis in human pancreatic beta-cells by both proximal and distal regulatory steps in stimulus-secretion coupling. Diabetes, 47:57-65.

Haffner SM, Lehto S, Ronnemaa T, et al. 1998. Mortality from coronary heart disease in subjects with type 2 diabetes and in nondiabetic subjects with and without prior myocardial infarction. $N$ Engl $J$ Med, 339:229-34.

Hanefeld M, Herman GA, Wu M, et al. 2007. Once-daily sitagliptin, a dipeptidyl peptidase-4 inhibitor, for the treatment of patients with type 2 diabetes. Curr Med Res Opin, 23:1329-39.

[HDS] The Hypertension in Diabetes Study Group. 1993. Hypertension in diabetes study (HDS): I. Prevalence of hypertension in newly presenting type 2 diabetic patients and the association with risk factors for cardiovascular and diabetic complications. J Hypertens, 11:309-17.

He YL, Serra D, Wang Y, et al. 2007. Pharmacokinetics and pharmacodynamics of vildagliptin in patients with type 2 diabetes mellitus. Clin Pharmacokinet, 46:577-88.

Henness S, Keam SJ. 2006. Vildagliptin. Drugs, 66:1989-2001.

Hermansen K, Kipnes M, Luo E, et al. 2007. Efficacy and safety of the dipeptidyl peptidase- 4 inhibitor, sitagliptin, in patients with type 2 diabetes mellitus inadequately controlled on glimepiride alone or on glimepiride and metformin. Diabetes Obes Metab, 9:733-45.
Higgins JPT, Thompson SG. 2002. Quantifying heterogeneity in a meta-analysis. Stat Med, 21:1539-58.

Higgins JPT, Thompson SG, Deeks JJ, et al. 2003. Measuring inconsistency in meta-analysis. BMJ, 327:557-60.

Higgins JPT, Green S (eds). 2006. Cochrane Handbook for Systematic Reviews of Interventions 4.2.6 [updated September 2006]. In: The Cochrane Library, Issue 3, 2005. Chichester, UK: John Wiley and Sons, Ltd.

Holst JJ, Deacon CF. 1998. Inhibition of the activity of dipeptidyl-peptidase IV as a treatment for type 2 diabetes. Diabetes, 47:1663-70.

Holst JJ, Deacon CF. 2005. Glucagon-like peptide-1 mediates the therapeutic actions of DPP-IV inhibitors. Diabetologia, 48:612-5.

Kahn SE, Hull RL, Utzschneider KM. 2006. Mechanisms linking obesity to insulin resistance and type 2 diabetes. Nature, 2006 444:840-6.

Kreymann B, Williams G, Ghatei MA, et al. 1987. Glucagon-like peptide-1 7-36: a physiological incretin in man. Lancet, 2:1300-04.

Laakso M. 1999. Hyperglycemia and cardiovascular disease in type 2 diabetes. Diabetes, 48:937-42.

Lambeir AM, Durinx C, Scharpe S, et al. 2003. Dipeptidyl-peptidase IV from bench to bedside: an update on structural properties, functions, and clinical aspects of the enzyme DPP IV. Crit Rev Clin Lab Sci, 40:209-94.

Lancas GR, Leiting B, Roy RS, et al. 2005. Dipeptidyl peptidase IV inhibition for the treatment of type 2 diabetes: potential importance of selectivity over dipeptidyl peptidases 8 and 9. Diabetes, 54:2988-94.

Light PE, Manning Fox JE, Riedel MJ, et al. 2002. Glucagon-like peptide-1 inhibits pancreatic ATP-sensitive potassium channels via a protein kinase A- and ADP-dependent mechanism. Mol Endocrinol, $16: 2135-44$

Lyseng-Williamson KA. 2007. Sitagliptin. Drugs, 67:587-97.

MacDonald PE, Salapatek AM, Wheeler MB. 2002. Glucagon-like peptide1 receptor activation antagonizes voltage-dependent repolarizing $\mathrm{K}(\mathrm{p})$ currents in beta-cells: a possible glucose-dependent insulinotropic mechanism. Diabetes, 51(Suppl. 3):S443-7.

Mannucci E, Pala L, Ciani S, et al. 2005. Hyperglycaemia increases dipeptidyl peptidase IV activity in diabetes mellitus. Diabetologia, 48:1168-72.

Manson JE, Coldlitz GA, Stampfer MJ, et al. 1991. A prospective study of maturity-onset diabetes mellitus and risk of coronary heart disease and stroke in women. Arch Intern Med, 151:1141-7.

Mayo KE, Miller LJ, Bataille D, et al. 2003. The glucagon receptor family. Pharmacol Rev, 55:167-94.

McCormack J, Greenhalgh T. 2000. Seeing what you want to see in randomised controlled trials: versions and perversions of UKPDS data. United Kingdom prospective diabetes study. BMJ, 320:1720-3.

Meier JJ, Nauck MA. 2004. GIP as a potential therapeutic agent? Horm Metab Res, 36:859-66.

Mentlein R. 1999. Dipeptidyl-peptidase IV (CD26) - role in the inactivation of regulatory peptides. Regul Pept, 85:9-24.

Mimori N, Terao S, Holmes D. 2006. Vildagliptin improves glucose control as evidenced by A1c after 12 weeks therapy in Japanese patients with type 2 diabetes. Diabetes, 55(Suppl 1):A125.

Moher D, Cook DJ, Eastwood S, et al. 1999. Improving the quality of reports of meta-analyses of randomised controlled trials: the QUOROM statement: Quality of Reporting of Meta-analyses. Lancet, 354:1896-1900.

Montori VM, Gandhi GY, Guyatt GH. 2007. Patient-important outcomes in diabetes - time for consensus. Lancet, 370:1104-56.

Mortensen K, Christensen LL, Holst JJ, et al. 2003. GLP-1 and GIP are colocalized in a subset of endocrine cells in the small intestine. Regul Pept, 114:189-96.

Nathan DM. 1998. Some answers, more controversy, from UKPDS. United Kingdom Prospective Diabetes Study. Lancet, 352:832-3.

Nauck MA, Heimesaat MM, Ørskov C, et al. 1993. Preserved incretin activity of glucagon-like peptide 1 [7-36 amide] but not of synthetic human gastric inhibitory polypeptide in patients with type- 2 diabetes mellitus. J Clin Invest, 91:301-7. 
Nauck MA, Heimesaat MM, Behle K, et al. 2002. Effects of glucagon-like peptide 1 on counterregulatory hormone responses, cognitive functions, and insulin secretion during hyperinsulinemic, stepped hypoglycemic clamp experiments in healthy volunteers. J Clin Endocrinol Metab, 87:1239-46.

Nauck MA, El-Ouaghlidi A. 2005. The therapeutic actions of DPP-IV inhibition are not mediated by glucagon-like peptid-1. Diabetologia, 48:608-11.

Nauck MA, Meininger G, Sheng D, et al. 2007. Efficacy and safety of the dipeptidyl peptidase-4 inhibitor, sitagliptin, compared with the sulfonylurea, glipizide, in patients with type 2 diabetes inadequately controlled on metformin alone: a randomized, double-blind, non-inferiority trial. Diabetes Obes Metab, 9:194-205.

Nonaka K, Kakikawa T, Sato A, et al. 2006. Twelve-week efficacy and tolerability of sitagliptin, a dipleptidyl peptidase-IV (DPP4) inhibitor, in Japanese patients with T2DM. Diabetes, 55(Suppl 1):A128.

Perfetti R, Zhou J, Doyle ME, et al. 2000. Glucagon-like peptide-1 induces cell proliferation and pancreatic-duodenum homeobox-1 expression and increases endocrine cell mass in the pancreas of old, glucose-intolerant rats. Endocrinology, 141:4600-5.

Pi-Sunyer FX, Schweizer A, Mills D, et al. 2007. Efficacy and tolerability of vildagliptin monotherapy in drug-naive patients with type 2 diabetes. Diabetes Res Clin Pract, 76:132-8.

Pratley RE, Jauffret-Kamel S, Galbreath E, et al. 2006. Twelve-week monotherapy with the DPP-4 inhibitor vildagliptin improves glycemic control in subjects with type 2 diabetes. Horm Metab Res, 38:423-8.

Raz I, Hanefeld M, Xu L, et al. 2006. Efficacy and safety of the dipeptidyl peptidase-4 inhibitor sitagliptin as monotherapy in patients with type 2 diabetes mellitus. Diabetologia, 49:2564-71.

Resnick HE, Foster GL, Bardsley Jm et al. 2006. Achievement of American Diabetes Association clinical practice recommendations among US adults with diabetes, 1999-2002: the National Health and Nutrition Examination Survey. Diabetes Care, 29:531-7.

Ristic S, Byiers S, Foley J, et al. 2005. Improved glycaemic control with dipeptidyl peptidase-4 inhibition in patients with type 2 diabetes: vildagliptin (LAF237) dose response. Diabetes Obes Metab, 7:692-8.

Ruige JB, deNeeling JND, Kostense PJ, et al. 1997. Performance of an NIDDM screening questionnaire based on symptoms and risk factors. Diabetes Care, 20:491-6.

Rosen CJ. 2007. The Rosiglitazone Story - Lessons from an FDA Advisory Committee Meeting. N Engl J Med, 357:844-6.

Rosenstock J, Brazg R, Andryuk PJ, et al. 2006. Efficacy and safety of the dipeptidyl peptidase-4 inhibitor sitagliptin added to ongoing pioglitazone therapy in patients with type 2 diabetes: a 24-week, multicenter, randomized, double-blind, placebo-controlled, parallel-group study. Clin Ther, 28:1556-68.
Rosenstock J, Baron MA, Dejager S, et al. 2007a. Comparison of vildagliptin and rosiglitazone monotherapy in patients with type 2 diabetes: a 24week, double-blind, randomized trial. Diabetes Care, 30:217-23.

Rosenstock J, Baron MA, Camisasca RP, et al. 2007b. Efficacy and tolerability of initial combination therapy with vildagliptin and pioglitazone compared with component monotherapy in patients with type 2 diabetes. Diabetes Obes Metab, 9:175-85.

Schweizer A, Couturier A, Foley JE, et al. 2007. Comparison between vildagliptin and metformin to sustain reductions in $\mathrm{HbA}(1 \mathrm{c})$ over 1 year in drug-naive patients with Type 2 diabetes. Diabet Med, 24:955-6.

Scott R, Wu M, Sanchez M, et al. 2007. Efficacy and tolerability of the dipeptidyl peptidase-4 inhibitor sitagliptin as monotherapy over 12 weeks in patients with type 2 diabetes. Int J Clin Pract, 61:171-80.

Solomon DH, Winkelmayer WC. 2007. Cardiovascular risk and the thiazolidinediones. Déjà vu all over again? JAMA, 298:1216-8.

Stamler J, Vaccaro O, Neaton JD, et al. 1993. Diabetes, other risk factors, and 12-year cardiovascular mortality for men screened in the multiple risk factor intervention trial. Diabetes Care, 16:434-44.

Stoffers DA, Kieffer TJ, Hussain MA, et al. 2000. Insulinotropic glucagonlike peptide 1 agonists stimulate expression of homeodomain protein IDX-1 and increase islet size in mouse pancreas. Diabetes, 49:741-8.

Toft-Nielsen MB, Damholt MB, Madsbad S, et al. 2001. Determinants of the impaired secretion of glucagon-like peptide- 1 in type 2 diabetic patients. J Clin Endocrinol Metab, 86:3717-23.

[UKPDS-16] UK Prospective Diabetes Study Group. 1995. UK prospective diabetes study 16: overview of 6 years' therapy of type II diabetes: a progressive disease. Diabetes, 44:1249-58.

[UKPDS-33] UK Prospective Diabetes Study Group. 1998. Intensive blood-glucose control with sulphonylureas or insulin compared with conventional treatment and risk of complications in patients with type 2 diabetes-UKPDS 33. Lancet, 352:837-52.

[UKPDS-34] UK Prospective Diabetes Study Group. 1998. Effect of intensive blood-glucose control with metformin on complications in overweight patients with type 2 diabetes. Lancet, 352:854-65.

[UKPDS-38] UK Prospective Diabetes Study Group. 1998. Tight blood pressure control and risk of macrovascular and microvascular complications in type 2 diabetes: UKPDS 38. BMJ, 317:703-13.

Wideman RD, Kieffer TJ. 2004. Glucose-dependent insulinotropic polypeptide as a regulator of beta cell function and fate. Horm Metab Res, 36:782-6.

Xu G, Stoffers DA, Habener JF, et al. 1999. Exendin-4 stimulates both betacell replication and neogenesis, resulting in increased betacell mass and improved glucose tolerance in diabetic rats. Diabetes, 48:2270-6. 